\title{
Association between insulin resistance and haematological parameters in pregnant women: A cross-sectional study
}

\author{
NAHLA M. MUBAREK ${ }^{1}$, ISHAG ADAM ${ }^{2}$, REEM ELTAYEB ${ }^{1,3}$, DURIA A. RAYIS ${ }^{1}$ and HAMDAN Z. HAMDAN HA $^{4,5}$ \\ ${ }^{1}$ Faculty of Medicine, University of Khartoum, 11111 Khartoum, Sudan; ${ }^{2}$ Department of Obstetrics and Gynaecology, \\ Unaizah College of Medicine and Medical Sciences, Qassim University, Buraidah, Al Qassim 51911; \\ ${ }^{3}$ Department of Medical Laboratory Science, College of Applied Medical Sciences, University of Ha'il, \\ Ha'il 55476, Saudi Arabia; ${ }^{4}$ Faculty of Medicine, Al-Neelain University, 11111 Khartoum, Sudan; \\ ${ }^{5}$ Department of Basic Medical Sciences, Unaizah College of Medicine and Medical Sciences, \\ Qassim University, Buraidah, Al Qassim 51911, Saudia Arabia
}

Received January 18, 2021; Accepted June 3, 2021

DOI: $10.3892 /$ wasj.2021.112

\begin{abstract}
Limited research has been conducted on the association between insulin resistance (IR) and haematological parameters, such as red cell distribution width, white blood cell count and mean platelet volume. To date, at least to the best of our knowledge, there are no published data available on IR and haematological parameters during pregnancy. In the present study, pregnant women were initially screened for gestational diabetes. Glucose tolerance tests and fasting plasma insulin (FPI) measurements were conducted between 24-28 weeks of gestational age. Homeostatic model assessment of insulin resistance (HOMA-IR), HOMA- $\beta$ indices and quantitative insulin sensitivity check index (QUICKI) were determined and used to assess insulin sensitivity and $\beta$-cell function. A total of 105 non-diabetic pregnant women were included in the present analysis. The mean ( \pm standard deviation) age, parity and gestational age were $28.3( \pm 5.6)$ years, $0.9( \pm 1.2)$ and 27.1 $( \pm 5.2)$ weeks, respectively. While there was a positive correlation between platelet count and HOMA-IR $(r=0.251, \mathrm{P}=0.009)$, there was no correlation between platelet count and the HOMA- $\beta$ level in the pregnant women examined $(n=105)$. No significant difference was observed in the haematological variables between women with IR $(n=17)$ and women who did not display IR $(n=88)$. On the whole, the present study demonstrates that platelet count is positively associated with IR. This indicates that haematological parameters may help identify pregnant women with IR. However, Further analyses are required in order to fully understand this association.
\end{abstract}

Correspondence to: Dr Hamdan Z. Hamdan, Faculty of Medicine, Al-Neelain University, Algomhoria Street, 11111 Khartoum, Sudan E-mail: hamdanology@hotmail.com

Key words: haematological parameters, insulin resistance, platelets, pregnancy, white blood cell

\section{Introduction}

Insulin resistance (IR) is a condition that is characterized by limited cellular uptake and usage of glucose. As a result of this condition, the pancreas releases extra insulin to compensate for hyperglycaemia (1). Metabolic analyses have detected various biomarkers that may be useful in early screening for gestational diabetes mellitus (GDM) (2). Maternal obesity is the main cause of IR during pregnancy $(3,4)$. Hyperinsulinemia in women is associated with various disorders, such as metabolic syndrome, polycystic ovary syndrome, preeclampsia and GDM (5-8). The effect of insulin is not limited to the control of blood glucose levels, but is also related to metabolic pathways (9).

Previous studies have provided evidence for the effect of hyperinsulinemia on certain haematological parameters $(10,11)$. Previous research has also investigated blood indices in patients displaying symptoms of IR during pregnancy, such as GDM and preeclampsia $(12,13)$. The results of previous studies on blood parameters, such as red blood cell (RBC) count, haematocrit, white blood cell (WBC) count, platelets and IR vary (14-16); thus, additional research under different experimental conditions is warranted. Moreover, to the best of our knowledge, there is currently no published data available on haematological parameters and IR during pregnancy.

In the past, performing a complete blood count (CBC) was a manual and difficult procedure and yielded unreliable results. CBC is currently performed using automated analysers, which yield results rapidly and accurately, and can present more detailed indices, such as red cell distribution width (RDW), platelet distribution width (PDW), mean corpuscular volume (MCV), etc. (17). The results of a CBC can be used as reliable predictors of a number of diseases, such as malignancies, pulmonary disease and cardiovascular disease $(18,19)$. The present study was conducted in order to investigate the correlation between haematological parameters and insulin sensitivity index in healthy pregnant women. 


\section{Patients and methods}

Study population. A cross-sectional study was conducted at a tertiary maternity hospital in Khartoum, Sudan (Saad Abualila Hospital) between August to November, 2018. The study participants were Sudanese women with singleton pregnancy (24-28 weeks of gestation) who required screening for GDM. Women with any chronic diseases, such as diabetes, hypertension, thyroid disease, haemolytic disease, renal disease, liver disease and women on any long-term medications were excluded from the study. All women signed an informed consent form, after which their medical and obstetric history (age, parity, gestational age, education and occupation) were gathered through a questionnaire. Their weights and heights were used to compute body mass index (BMI), as $\mathrm{kg} / \mathrm{m}^{2}$. The present study was approved by the Research Ethics Committee of the Department of Obstetrics and Gynaecology, Faculty of Medicine, University of Khartoum, Sudan (\#2017, 08).

After fasting for $10 \mathrm{~h}$, the study participants were administered a $75 \mathrm{~g}$ oral glucose load for an oral glucose tolerance test. GDM was diagnosed in the present study according to the guidelines of the International Association of Diabetes and Pregnancy Study Groups (IADPSG). According to the guidelines, GDM was diagnosed by a fasting blood glucose (FBG) level $\geq 92 \mathrm{mg} / \mathrm{dl}$, /1-h blood glucose level $\geq 180 \mathrm{mg} / \mathrm{dl}$, and $/ 2$-h blood glucose level $\geq 153 \mathrm{mg} / \mathrm{dl}$ (20). Subsequently, $5 \mathrm{ml}$ of blood from all participants was withdrawn into a tube containing ethylene diamine tetra acetic acid (EDTA) and used for the analysis for haematological parameters, using an automated haematology analyser [Sysmex (Japan) KX-21] $(17,21)$. A total of $2 \mathrm{ml}$ of the blood sample was used for a hemogram analysis and the remainder was centrifuged at $3,000 \mathrm{x} \mathrm{g}$ for $10 \mathrm{~min}$ at room temperature and plasma was then stored at $-20^{\circ} \mathrm{C}$ until the insulin assay was performed. A glucose oxidase method (Shino-Test Corporation) and an immunoassay analyser (AIA 360, Tosoh Corporation) were used to measure the glucose and fasting insulin level, respectively. The homeostasis model assessment (HOMA) of insulin resistance index (HOMA-IR) was determined using the following formula: [fasting glucose level $(\mathrm{mg} / \mathrm{dl}) \mathrm{x}$ fasting insulin level $(\mu \mathrm{U} / \mathrm{ml}) / 405]$ (22). The quantitative insulin sensitivity check index (QUICKI) was determined using the following formula: $1 /[\log$ fasting insulin level $(\mu \mathrm{U} / \mathrm{ml})+\log$ fasting glucose level $(\mathrm{mg} / \mathrm{dl})](22,23)$. In addition, the HOMA of $\beta$-cell function (HOMA- $\beta$ ) (\%) was calculated using the following formula: $360 \mathrm{x}$ fasting insulin level $(\mu \mathrm{U} / \mathrm{ml}) /[$ fasting glucose level (mg/dl)-63], and indicates insulin secretion (22). In accordance with previous research, the present study considered women to have IR if their HOMA-IR was $>2.6$ (24). A sample size of 105 pregnant women was used to determine the significant minimum difference in the correlations $(r=0.27)$ between IR and haematological parameters. This sample size has $80 \%$ power and $5 \%$ precision at $\alpha=0.05$.

Statistical analysis. Statistical analysis was performed using the Statistical Package for the Social Sciences (SPSS) for Windows, version 20.0 (SPSS Inc.). Proportions of the studied variables are expressed in percentages (\%). The Shapiro-Wilk test was used to test for normality of the continuous variables. The mean ( \pm standard deviations) were used to describe continuous variables if they were normally distributed, while the median (and interquartile range) was used to describe the continuous variables if they were abnormally distributed. Spearman's correlation analysis was performed between the following variables: Body mass index (BMI), haematological variables and insulin sensitivity indices. A Student's t-test and non-parametric test (Mann-Whitney U test) were used to compare the variables between the groups when the data were normally and not normally distributed, respectively. The Chi-squared test was used to compare categorical variables between women with IR and women without-IR. A two-sided P-value $<0.05$ was considered to indicate a statistically significant difference.

\section{Results}

A total of 126 pregnant women were screened for GDM. In total, $21(16.6 \%)$ presented with GDM and the remainder were non-diabetic and were included in the present analysis. The general characteristics of the 105 participants and the comparison between 17 women with IR and 88 without IR are presented in Table I. The mean \pm SD for age, parity and gestational age was $28.3 \pm 5.6$ years, $0.9 \pm 1.2$ and $27.1 \pm 5.2$ weeks, respectively. No significant differences were observed in sociodemographic characteristics between women with IR and those without IR (Table I). A total of 18 (17.1\%) and 12 (11.4\%) of the women resided in rural regions and had a secondary school level of education or less, respectively.

While there was a positive correlation between platelet count and HOMA-IR ( $r=0.251, \mathrm{P}=0.009)$, no correlation was observed between platelet count and the HOMA- $\beta$ level in the pregnant women examined $(n=105)$ (Table II). No significant difference was observed in the haematological variables of women with IR $(\mathrm{n}=17)$ and women displaying no IR $(\mathrm{n}=88)$ (Table III).

\section{Discussion}

To the best of our knowledge, the present study is the first to investigate haematological parameters in pregnant women displaying IR. The major finding of the present study was that platelet count significantly correlated with HOMA-IR. Additionally, no correlation was observed between the parameters of IR and RBC counts, WBC counts, haemoglobin and other blood indices. A previous study demonstrated that both the insulin level and HOMA-IR positively correlated with the platelet count in non-pregnant subjects (25). Moreover, the platelet-to-lymphocyte ratio has been observed to be a useful indicator for IR, apart from individuals who present with liver fibrosis (16). While maintaining homeostasis and facilitating thrombosis are the main function of platelets, studies have indicated that platelets can also modify immune systems, the inflammatory process and intracellular communication $(26,27)$. Additionally, IR has been shown to be associated with the development of non-alcoholic fatty liver disease (NAFLD) in pregnant and non-pregnant women $(28,29)$. The platelet count in non-pregnant women with NAFLD is an indicator for the severity of the disease (29). The platelet count in pregnancy may perhaps indicate the severity of IR and the increased risk of GDM, as it appears to do in non-pregnant individuals. 
Table I. General characteristics of pregnant and non-diabetic Sudanese women and comparisons of the sociodemographic characteristics between women with insulin resistance and women who displayed no insulin resistance.

\begin{tabular}{|c|c|c|c|c|}
\hline Variable & $\begin{array}{l}\text { Total no. of } \\
\text { patients } \\
(\mathrm{n}=105)\end{array}$ & $\begin{array}{l}\text { Women with } \\
\text { insulin resistance } \\
\qquad(\mathrm{n}=17)\end{array}$ & $\begin{array}{l}\text { Women without } \\
\text { insulin resistance } \\
\qquad(\mathrm{n}=88)\end{array}$ & P-value \\
\hline Age, years $($ mean $\pm S D)$ & $28.3 \pm 5.6$ & $28.3 \pm 5.1$ & $27.9 \pm 5.8$ & 0.798 \\
\hline Parity [median (25-75th interquartile range)] & $0.9 \pm 1.2$ & $0(0-1.25)$ & $0(0-2)$ & 0.654 \\
\hline Body mass index $\left(\mathrm{kg} / \mathrm{m}^{2}\right)($ mean $\pm \mathrm{SD})$ & $27.1 \pm 5.2$ & $27.8 \pm 5.9$ & $26.9 \pm 4.9$ & 0.529 \\
\hline Haemoglobin $(\mathrm{g} / \mathrm{dl})($ mean $\pm \mathrm{SD})$ & $10.8 \pm 0.9$ & $10.7 \pm 0.9$ & $10.8 \pm 0.9$ & 0.759 \\
\hline Rural residence $[\mathrm{n},(\%)]$ & $18(17.1 \%)$ & $4(23.5 \%)$ & $14(15.9 \%)$ & 0.248 \\
\hline Education level $\leq$ secondary level $[\mathrm{n},(\%)]$ & $12(11.4 \%)$ & $0(0 \%)$ & $12(13.6 \%)$ & 0.141 \\
\hline Housewives $[\mathrm{n},(\%)]$ & $77(73.3 \%)$ & $10(58.8 \%)$ & $67(76.1 \%)$ & 0.704 \\
\hline History of miscarriage $[\mathrm{n},(\%)]$ & $26(24.7 \%)$ & $2(11.7 \%)$ & $24(27.2 \%)$ & 0.300 \\
\hline
\end{tabular}

Data are expressed as the mean $\pm \mathrm{SD}$, or median (25-75th interquartile) or number $(\%)$ as applicable.

Table II. Spearman's correlations between insulin resistance variables and haematological parameters in pregnant women ( $\mathrm{n}=105)$.

\begin{tabular}{|c|c|c|c|c|c|c|}
\hline \multirow[b]{2}{*}{ Variable } & \multicolumn{2}{|c|}{ HOMA-IR } & \multicolumn{2}{|c|}{ QUICKI } & \multicolumn{2}{|c|}{ HOMA- $\beta$} \\
\hline & $\mathrm{R}$ value & P-value & $\mathrm{R}$ value & P-value & $\mathrm{R}$ value & P-value \\
\hline White blood cell (cells $\times 10^{9} / 1$ ) & 0.131 & 0.179 & -0.131 & 0.179 & 0.152 & 0.133 \\
\hline Neutrophils (cells x 109/1) & 0.104 & 0.284 & -0.104 & 0.284 & 0.133 & 0.189 \\
\hline Lymphocytes (cells x 109/1) & 0.069 & 0.478 & -0.069 & 0.478 & 0.133 & 0.189 \\
\hline Red blood cell cells & -0.013 & 0.891 & 0.013 & 0.891 & -0.011 & 0.915 \\
\hline Haemoglobin (gm/dl) & 0.102 & 0.294 & -0.102 & 0.294 & 0.133 & 0.189 \\
\hline Haematocrit (\%) & 0.150 & 0.124 & -0.150 & 0.124 & 0.124 & 0.220 \\
\hline Red cell distribution width (\%) & -0.029 & 0.767 & 0.029 & 0.767 & -0.044 & 0.664 \\
\hline Platelet count $\left(10^{3} / \mu 1\right)$ & 0.251 & $0.009^{\mathrm{a}}$ & -0.251 & $0.009^{\mathrm{a}}$ & 0.075 & 0.462 \\
\hline Mean platelet volume (f) & -0.019 & 0.849 & 0.019 & 0.849 & -0.035 & 0.731 \\
\hline Platelet distribution width (\%) & 0.095 & 0.332 & -0.095 & 0.332 & 0.075 & 0.841 \\
\hline
\end{tabular}

${ }^{\mathrm{a}} \mathrm{P} \leq 0.05$, indicates a statistically significant difference. HOMA-IR, homeostatic model assessment of insulin resistance; QUICKI, quantitative insulin sensitivity check index; HOMA- $\beta$, homeostatic model assessment of $\beta$-cell function.

Table III. Comparisons of median (interquartile) level of BMI and insulin sensitivity indices between women with insulin resistance and women who displayed no insulin resistance.

\begin{tabular}{|c|c|c|c|}
\hline Variable & $\begin{array}{l}\text { Women with insulin resistance } \\
\qquad(\mathrm{n}=17)\end{array}$ & $\begin{array}{l}\text { Women without insulin resistance } \\
\qquad(\mathrm{n}=88)\end{array}$ & P-value \\
\hline Body mass index $\left(\mathrm{kg} / \mathrm{m}^{2}\right)$ & $27.4(23.3-31.2)$ & $26.6(24.3-29.6)$ & 0.904 \\
\hline White blood cell (cells $\times 10^{9} / 1$ ) & $9.491(7.9-9.9)$ & $8.491(7.2-9.1)$ & 0.099 \\
\hline Neutrophils (cells x 109/1) & $5.952(5.6-6.6)$ & $5.952(4.8-6.3)$ & 0.375 \\
\hline Lymphocytes (cells x109/1) & $1.909(1.7-2.2)$ & $1.909(1.6-2.0)$ & 0.444 \\
\hline Red blood cell cells & $4.057(3.9-4.1)$ & $4.057(3.8-4.2)$ & 0902 \\
\hline Haemoglobin (gm/dl) & $10.989(10.4-11.2)$ & $10.897(10.6-11.3)$ & 0.749 \\
\hline Haematocrit (\%) & $35.184(33.8-36.6)$ & $35.184(33.8-36.5)$ & 0.854 \\
\hline Red cell distribution width (\%) & $13.663(13.3-13.7)$ & $13.727(12.9-13.7)$ & 0.397 \\
\hline Platelet count $\left(10^{3} / \mu 1\right)$ & $239.115(230.0-282.0)$ & $239.11(209.2-250.0)$ & 0.080 \\
\hline Mean platelet volume (f) & $8.196(8.0-8.6)$ & $8.192(7.7-8.5)$ & 0.499 \\
\hline Platelet distribution width (\%) & $15.872(15.6-15.9)$ & $15.872(15.7-8.5)$ & 0.336 \\
\hline
\end{tabular}


The present study found no correlation between leucocyte count and the parameters of IR. The finding is not in agreement with previous studies on non-pregnant subjects $(14,30,31)$. In a previous study, compared with non-IR obese patients, obese patients with IR had higher neutrophil concentrations and a higher neutrophil/lymphocyte (N/L) ratio (14). Additionally, a positive correlation was reported between IR and leucocyte count (14). In another study, all WBCs were positively associated with HOMA-IR (30). The leukocyte count has also been shown to be positively associated with HOMA- $\beta$ among non-diabetic individuals (31). Previous research has also provided evidence that hyperinsulinemia does not play a role in altering haematological parameters (32). Factors that may alter haematological parameters include the enhancement of erythropoiesis in bone marrow and increasing haemoglobin and RBC counts $(10,11)$. WBCs are a trigger for the inflammatory process via epinephrine (the main sympathetic neurotransmitter) and are a useful predictor of cardiovascular disease $(33,34)$. Inflammatory mediators, which are secreted from adipose tissue and placenta in the third trimester, can lead to inflammation during pregnancy $(35,36)$. Moreover, inflammatory cytokines have been reported to have role in the pathogenesis of IR $(37,38)$.

The present study found no correlation between RBCs and IR. Hyperinsulinemia enhances the synthesis of RBC through a number of mechanisms: First, growth factor-1, which mimics the insulin hormone, exerts a synergistic effect with erythropoietin and results in the stimulation of erythroid precursors $(39,40)$; second, insulin is an anabolic hormone that generally stimulates protein synthesis. One of these proteins is hypoxia-inducible factor-1a (HIF-1 $\alpha$ ), which in turn stimulates the syntghesis of vascular endothelial growth factor and erythropoietin $(41,42)$. However, studies have found that a number of other factors may affect RBC count and haemoglobin levels, factors such as BMI, nutrition and infection $(43,44)$. Thus, it may be hypothesized that IR may also display geographical variance among individuals in sub-Saharan Africa. However, future studies are required to investigate this matter.

In the present study, none of the investigated sociodemographic factors (age, BMI and parity) differed significantly between pregnant women with IR and pregnant women without IR. These findings are almost in line with those described in the stud by Karakaya et al (14), who reported no differences in the age of subjects with IR compared with those without IR. Yet, they reported a significant difference in BMI. This comparison should be taken with caution as Karakaya et al (14) performed their study in obese non-pregnant subjects, including those of the male gender.

The present study had several limitations that should be considered when interpreting the findings. First, inflammatory markers, which can identify the severity of the inflammatory state, such as C-reactive protein, cytokines and ferritin, were not measured. Second, the BMI measurement of the study participants was taken during pregnancy and data on pre-pregnancy BMI were not available for analysis. Pre-conception counselling services would be helpful in order to gather these data and develop more accurate interpretation of the results. Third, given the nature of the study design, which involved a cross-sectional study, it is difficult to understand the causes and outcomes of IR in pregnancy. Further studies employing different design methods are therefore warranted.
The present study suggests that CBC can be used to identify IR in pregnant women who otherwise appear healthy. This indicates that the measurement of haematological parameters has the potential to be a simple screening test for detecting IR and perhaps, GDM. Additional studies are required however, in order to confirm and elaborate on these findings.

\section{Acknowledgements}

Not applicable.

\section{Funding}

Not applicable.

\section{Availability of data and materials}

The datasets used and/or analysed during the current study are available from the corresponding author on reasonable request.

\section{Authors' contributions}

NMM, RE and IA conceptualized and designed the study. RE, DAR and HZH conducted the study. RE, AI and NMM performed the statistical analyses. HZH, IA and DAR drafted the manuscript. IA and $\mathrm{HZH}$ confirm the authenticity of the all the raw data. All authors reviewed the draft and have read and approved the final version of the manuscript.

\section{Ethics approval and consent to participate}

The present study was approved by the Research Ethics Committee of the Department of Obstetrics and Gynaecology, Faculty of Medicine, University of Khartoum, Sudan (\#2017, 08).

\section{Patient consent for publication}

Not applicable.

\section{Competing interests}

The authors declare that they have no competing interests.

\section{References}

1. Shanik MH, Xu Y, Skrha J, Dankner R, Zick Y and Roth J: Insulin resistance and hyperinsulinemia: Is hyperinsulinemia the cart or the horse? Diabetes Care 31 Suppl 2: S262-S268, 2008.

2. Kumru P, Arisoy R, Erdogdu E, Demirci O, Kavrut M, Ardıc C, Aslaner N, Ozkoral A and Ertekin A: Prediction of gestational diabetes mellitus at first trimester in low-risk pregnancies. Taiwan J Obstet Gynecol 55: 815-820, 2016.

3. Rafferty AR, Geraghty AA, Kennelly MA, O'Brien EC, Reji RM, Mehegan J, Segurado R, Smith T, Maguire O, Cronin M and McAuliffe FM: Limited impact of fetal sex and maternal body mass index on fetal and maternal insulin resistance and lipid metabolism: Findings from the PEARs study. Reprod Sci 27: 513-522, 2020

4. Tinius RA, Blankenship MM, Furgal KE, Cade WT, Pearson KJ, Rowland NS, Pearson RC, Hoover DL and Maples JM: Metabolic flexibility is impaired in women who are pregnant and overweight/obese and related to insulin resistance and inflammation. Metabolism 104: 154142, 2020. 
5. Balani J, Hyer S, Syngelaki A, Akolekar R, Nicolaides KH, Johnson A and Shehata H: Association between insulin resistance and preeclampsia in obese non-diabetic women receiving metformin. Obstet Med 10: 170-173, 2017.

6. Mohammed A, Aliyu IS and Manu M: Correlation between circulating level of tumor necrosis factor-alpha and insulin resistance in Nigerian women with gestational diabetes mellitus. Ann Afr Med 17: 168-171, 2018.

7. Yildizhan R, Yildizhan BP, Anik G and Yildizhan G: Insulin resistance and polycystic ovary syndrome. In: Handbook of Type 1 Diabetes Mellitus: Etiology, Diagnosis, and Treatment. Aucoin L and Prideux T (eds). Nova Science Publishers, Inc. pp419-433, 2010.

8. Wani K, Sabico S, Alnaami AM, Al-Musharaf S, Fouda MA, Turkestani IZ, Al-Ajlan A, Alshingetti NM, Alokail MS and Al-Daghri NM: Early-Pregnancy metabolic syndrome and subsequent incidence in gestational diabetes mellitus in arab women. Front Endocrinol (Lausanne) 11: 98, 2020.

9. Yang Q, Vijayakumar A and Kahn BB: Metabolites as regulators of insulin sensitivity and metabolism. Nat Rev Mol Cell Biol 19: 654-672, 2018.

10. Mardi T, Toker S, Melamed S, Shirom A, Zeltser D, Shapira I, Berliner S and Rogowski O: Increased erythropoiesis and subclinical inflammation as part of the metabolic syndrome. Diabetes Res Clin Pract 69: 249-255, 2005.

11. McCarty MF: Hyperinsulinemia may boost both hematocrit and iron absorption by up-regulating activity of hypoxia-inducible factor-1alpha. Med Hypotheses 61: 567-573, 2003.

12. Sun T, Meng F, Zhao H, Yang M, Zhang R, Yu Z, Huang X, Ding H, Liu J and Zang S: Elevated first-trimester neutrophil count is closely associated with the development of maternal gestational diabetes mellitus and adverse pregnancy outcomes Diabetes 69: 1401-1410, 2020.

13. Thomann R, Rossinelli N, Keller U, Tirri BF, De Geyter C, Ruiz J, Kränzlin $\mathrm{M}$ and Puder JJ: Differences in low-grade chronic inflammation and insulin resistance in women with previous gestational diabetes mellitus and women with polycystic ovary syndrome. Gynecol Endocrinol 24: 199-206, 2008.

14. Karakaya S, Altay M, Kaplan Ef, Karadağ I, Ünsal O, Bulur O, Eser M and Ertuğrul DT: The neutrophil-lymphocyte ratio and its relationship with insulin resistance in obes. Turk $\mathbf{J}$ Med Sci 49: 245-248, 2019.

15. Ferreira D, Severo M, Araújo J, Barros H, Guimarães JT and Ramos E: Association between insulin resistance and haematological parameters: A cohort study from adolescence to adulthood. Diabetes Metab Res Rev 35: e3194, 2019.

16. Alsebaey A, Elhelbawy M and Waked I: Platelets-To-lymphocyte ratio is a good predictor of liver fibrosis and insulin resistance in hepatitis C virus-related liver disease. Eur J Gastroenterol Hepatol 30: 207-211, 2018.

17. Celkan TT: What does a hemogram say to us? Turk Pediatr Ars 55: 103-116, 2020.

18. Wiwanitkit V: Neutrophil-to-lymphocyte ratio, platelet-tolymphocyte ratio and heart failure. Arq Bras Cardiol 106: 265, 2016.

19. Agameya AM, Labib K and Moiety F: Using platelet-to-lymphocyte ratio as a diagnostic marker in malignant ovarian tumors. Int J Reprod Contraception, Obstet Gynecol 7: 2089, 2018.

20. International Association of Diabetes and Pregnancy Study Groups Consensus Panel; Metzger BE, Gabbe SG, Persson B, Buchanan TA, Catalano PA, Damm P, Dyer AR, de Leiva A, Hod $\mathrm{M}$, et al: International association of diabetes and pregnancy study groups recommendations on the diagnosis and classification of hyperglycemia in pregnancy. Diabetes Care 33: 676-682, 2010.

21. Rayis DA, Ahmed MA, Abdel-Moneim H, Adam I and Lutfi MF: Trimester pattern of change and reference ranges of hematological profile among Sudanese women with normal pregnancy. Clin Pract 7: 888, 2017

22. Matthews DR, Hosker JP, Rudenski AS, Naylor BA, Treacher DF and Turner RC: Homeostasis model assessment: Insulin resistance and beta-cell function from fasting plasma glucose and insulin concentrations in man. Diabetologia 28: 412-419, 1985.

23. Katz A, Nambi SS, Mather K, Baron AD, Follmann DA, Sullivan G and Quon MJ: Quantitative insulin sensitivity check index: A simple, accurate method for assessing insulin sensitivity in humans. J Clin Endocrinol Metab 85: 2402-2410, 2000.

24. Ascaso JF, Pardo S, Real JT, Lorente RI, Priego A and Carmena R: Diagnosing insulin resistance by simple quantitative methods in subjects with normal glucose metabolism. Diabetes Care 26: 3320-3325, 2003.
25. Park JM, Lee JW, Shim JY and Lee YJ: Relationship between platelet count and insulin resistance in Korean adolescents: A nationwide population-based study. Metab Syndr Relat Disord 16: 470-476, 2018

26. Thomas M and Storey R: The role of platelets in inflammation. Thromb Haemost 114: 449-458, 2015.

27. Jenne CN, Urrutia R and Kubes P: Platelets: Bridging hemostasis, inflammation, and immunity. Int J Lab Hematol 35: 254-261, 2013

28. Lee SM, Kwak SH, Koo JN, Oh IH, Kwon JE, Kim BJ, Kim SM, Kim SY, Kim GM, Joo SK, et al: Non-alcoholic fatty liver disease in the first trimester and subsequent development of gestational diabetes mellitus. Diabetologia 62: 238-248, 2019.

29. Garjani A, Safaeiyan A and Khoshbaten M: Association between platelet count as a noninvasive marker and ultrasonographic grading in patients with nonalcoholic fatty liver disease. Hepat Mon 15: e24449, 2015.

30. Lee CTC, Harris SB, Retnakaran R, Gerstein HC, Perkins BA, Zinman B and Hanley AJ: White blood cell subtypes, insulin resistance and $\beta$-cell dysfunction in high-risk individuals-the PROMISE cohort. Clin Endocrinol (Oxf) 81: 536-541, 2014.

31. de las Heras Gala T, Herder C, Rutters F, Carstensen-Kirberg M, Huth C, Stehouwer CDA, Nijpels G, Schalkwijk C, Flyvbjerg A, Franks PW, et al: Association of changes in inflammation with variation in glycaemia, insulin resistance and secretion based on the KORA study. Diabetes Metab Res Rev 34: e3063, 2018.

32. Park JM, Lee DC and Lee YJ: Relationship between high white blood cell count and insulin resistance (HOMA-IR) in Korean children and adolescents: Korean national health and nutrition examination survey 2008-2010. Nutr Metab Cardiovasc Dis 27: 456-461, 2017.

33. Weijenberg MP, Feskens EJ and Kromhout D: White blood cell count and the risk of coronary heart disease and all-cause mortality in elderly men. Arterioscler Thromb Vasc Biol 16: 499-503, 1996.

34. Lampert R, Bremner JD, Su S, Miller A, Lee F, Cheema F, Goldberg J and Vaccarino V: Decreased heart rate variability is associated with higher levels of inflammation in middle-aged men. Am Heart J 156: 759, 2008.

35. Desoye G and Hauguel-de Mouzon S: The human placenta in gestational diabetes mellitus. The insulin and cytokine network. Diabetes Care 30 (Suppl 2): S120-S126, 2007.

36. Vrachnis N, Belitsos P, Sifakis S, Dafopoulos K, Siristatidis C, Pappa KI and Iliodromiti Z: Role of adipokines and other inflammatory mediators in gestational diabetes mellitus and previous gestational diabetes mellitus. Int J Endocrinol 2012: 549748, 2012.

37. Pace NP, Bonello A, Roshan MH and Vassallo J: Circulating visfatin levels in the second and third trimester of pregnancies with gestational diabetes: A systematic review. Minerva Ginecol 71: 329-343, 2019.

38. Meeks KAC, Stronks K, Adeyemo A, Addo J, Bahendeka S, Beune E, Owusu-Dabo E, Danquah I, Galbete C, Henneman $\mathrm{P}$, et al: Peripheral insulin resistance rather than beta cell dysfunction accounts for geographical differences in impaired fasting blood glucose among Sub-Saharan African individuals: Findings from the RODAM study. Diabetologia 60: 854-864, 2017

39. Miyagawa SI, Kobayashi M, Konishi N, Sato T and Ueda K: Insulin and insulin-like growth factor I support the proliferation of erythroid progenitor cells in bone marrow through the sharing of receptors. Br J Haematol 109: 555-562, 2000.

40. Aoki I, Homori M, Ishikawa K, Taniyama M and Toyama K: Stimulatory effect of human insulin on erythroid progenitors (cfu-e and bfu-e) in human cd34+ separated bone marrow cells and the relationship between insulin and erythropoietin. Stem Cells 12: 329-338, 1994

41. Semenza GL: Regulation of mammalian O2 homeostasis by hypoxia-inducible factor 1. Annu Rev Cell Dev Biol 15: 551-578, 1999.

42. Wang GL and Semenza GL: Molecular basis of hypoxia-induced erythropoietin expression. Curr Opin Hematol 3: 156-162, 1996.

43. Abbas W, Adam I, Rayis DA, Hassan NG and Lutfi MF: A higher rate of iron deficiency in obese pregnant sudanese women. Open Access Maced J Med Sci 5: 285-289, 2017.

44. Breymann C: Iron deficiency anemia in pregnancy. Semin Hematol 52: 339-347, 2015

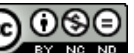

This work is licensed under a Creative Commons Attribution-NonCommercial-NoDerivatives 4.0 International (CC BY-NC-ND 4.0) License. 